\title{
Microstructure Evolution and Recrystallization Resistance of a 7055 Alloy Fabricated by Spray Forming Technology and by Conventional Ingot Metallurgy
}

\author{
ZHIQIANG XIE, ZHIHONG JIA, KAIYUN XIANG, YAPING KONG, ZHENGUO LI, \\ XI FAN, WANTAI MA, HAO ZHANG, LIN LIN, KNUT MARTHINSEN, \\ and QING LIU
}

\begin{abstract}
The effect of different fabricating processes (spray forming and conventional casting) and homogenization treatment on the microstructure of an 7055 alloy was investigated by optical microscopy $(\mathrm{OM})$, scanning electron microscopy (SEM), electron probe X-ray micro-analyzer (EPMA), and transmission electron microscopy (TEM). It was found that the grain size of the as-deposited (spray formed) 7055 alloy had half the size as that of the as-cast 7055 alloy and there was no $\mathrm{Al}_{2} \mathrm{CuMg}$ phase that embedded in the coarse $\mathrm{Mg}(\mathrm{Zn}, \mathrm{Cu}, \mathrm{Al})_{2}$ phase distributed along the grain boundaries in the as-deposited 7055 alloy. No segregation of zirconium was observed in the as-deposited 7055 alloy. After homogenization heating at $350{ }^{\circ} \mathrm{C} / 5$ hours +470 ${ }^{\circ} \mathrm{C} / 24$ hours, $\mathrm{Al}_{3} \mathrm{Zr}$ dispersoids were inhomogeneously distributed within grains in the traditionally cast 7055 alloy, while more homogeneously distributed within grains in the spray-formed 7055 alloy. Compared with the traditional cast 7055 alloy, the uniform distribution of $\mathrm{Al}_{3} \mathrm{Zr}$ dispersoids in the spray-formed 7055 alloy retards recrystallization more effectively. This investigation highlights the advantage of spray forming technology on improving microstructure of a 7055 alloy.
\end{abstract}

https://doi.org/10.1007/s11661-020-05931-w

(C) The Minerals, Metals \& Materials Society and ASM International 2020

\footnotetext{
ZHIQIANG XIE, KAIYUN XIANG, YAPING KONG, and ZHENGUO LI are with the International Joint Laboratory for Light Alloys (Ministry of Education), College of Materials Science and Engineering, Chongqing University, Chongqing 400044, China. ZHIHONG JIA is with the International Joint Laboratory for Light Alloys (Ministry of Education), College of Materials Science and Engineering, Chongqing University and also with the Electron Microscopy Center of Chongqing University, Chongqing 400044, China and also with the Key Laboratory for Light-Weight Materials, Nanjing Tech University, Nanjing 210009, China. Contact e-mail: zhihongiia@cqu.edu.cn XI FAN and HAO ZHANG are with the Jiangsu Haoran Spray Forming Alloy Co., Ltd., Zhenjiang 212009, China. WANTAI MA is with the College of Mechanical \& Electrical Engineering, Nanjing University of Aeronautics and Astronautics, Nanjing 210016, China. LIN LIN is with the Southwest Aluminium (Group) Co., Ltd., Chongqing 401326, China. KNUT MARTHINSEN is with the Department of Materials Science and Engineering, NTNU - Norwegian University of Science and Technology, Alfred Getz vei 2b, 7491 Trondheim, Norway. QING LIU is with the International Joint Laboratory for Light Alloys (Ministry of Education), College of Materials Science and Engineering, Chongqing University and also with the Key Laboratory for Light-

Weight Materials, Nanjing Tech University.

Manuscript submitted March 8, 2020.
}

Article published online August 4, 2020

\section{INTRODUCTION}

$7055 \mathrm{Al}-\mathrm{Zn}-\mathrm{Mg}-\mathrm{Cu}$ alloy is an important member of the 7xxx series alloys and is extensively used in the aerospace industry owing to its light weight and high mechanical performance. ${ }^{11]}$ Many attempts have been made to further improve the mechanical properties of the 7055 aluminum alloy. Improvement in the performance of most aluminum alloys can be attributed to modifications of chemical composition and/or employing new production methods. ${ }^{[2-5]}$ The spray forming technology is an advanced fabrication technique, which is based on rapid solidification and powder metallurgy. ${ }^{[6]}$ The success of spray deposition can possibly also be exploited to enhance the performance of 7055 aluminum alloys. Compared with conventional ingot metallurgy, the spray forming technology provides possibilities to avoid many unfavorable factors that generally are detrimental to the performance of aluminum alloys, such as large grains, serious compositional segregation, and severe casting defects due to low solidification rate. Most importantly, a uniform distribution of chemical composition and microstructure can be obtained because of the rapid solidification that is an inherent feature of the spray deposition process. ${ }^{[7-11]}$ 
Therefore, the spray forming technology possibly provides an alternative route to develop high-strength aluminum alloys.

A homogenization heat treatment is an indispensable process for traditional casting alloys, aiming at dissolving large size eutectic phases, redistributing the solute, eliminating intragranular segregations, i.e., level out compositional variations, reducing internal stresses and removing other casting defects. ${ }^{[12,13]}$ Besides, in 7xxx aluminum alloys with small additions of zirconium, coherent $\mathrm{Al}_{3} \mathrm{Zr}$ dispersoids are precipitated during homogenization, which may have a significant effect on inhibiting recrystallization so that alloys maintain their deformed microstructure during possibly subsequent high temperature exposure. ${ }^{[14-16]}$ Hence, alloys may obtain excellent mechanical properties via the combination of their stable deformed substructure and $\mathrm{Al}_{3} \mathrm{Zr}$ precipitation hardening. However, the segregation of zirconium during casting of zirconium-containing aluminum alloys is well known, which may result in large variations in the $\mathrm{Al}_{3} \mathrm{Zr}$ distribution within single grains. ${ }^{[17-19]}$ Generally, $\mathrm{Al}_{3} \mathrm{Zr}$ dispersoids concentrate in the center of dendrite grains while precipitate-free zones (PFZ) result at the dendrite grain boundaries. At the same time, the effectiveness of preventing recrystallization is closely related to the size, number density, and spatial distribution of $\mathrm{Al}_{3} \mathrm{Zr}^{[14,19,20]}$ Many studies have focused on precipitation of the $\mathrm{MgZn}_{2}$ strengthening phase in 7xxx alloys and the associated aging behavior, while less studies have focused on the optimal homogenization conditions as means to control the precipitation of $\mathrm{Al}_{3} \mathrm{Zr}$ dispersoids. Even less studies have reported on the effect of homogenization on sprayformed $\mathrm{Al}-\mathrm{Zn}-\mathrm{Mg}-\mathrm{Cu}$ alloys. In particular, the precipitation and distribution of $\mathrm{Al}_{3} \mathrm{Zr}$ dispersoids during the homogenization process and the resulting effects in terms of recrystallization resistance have not been studied in spray-formed $\mathrm{Al}-\mathrm{Zn}-\mathrm{Mg}-\mathrm{Cu}$ alloys.

A clear difference in microstructure is expected to be found between an as-cast and an as-deposited sprayformed 7055 alloy. Although many unwanted features related to conventional casting, e.g., strong micro-segregations, are expected to be nearly non-existing in a spray-formed alloy, it does not mean that the homogenization is no longer needed, as a large number of $\mathrm{Al}_{3} \mathrm{Zr}$ dispersoids are formed during the homogenization process. Understanding the recrystallization resistance of 7055 alloys requires a comprehensive analysis of the precipitation behavior of $\mathrm{Al}_{3} \mathrm{Zr}$ dispersoids, in terms of their spatial distribution, size and number density, and possible precipitate-free zones (PFZ) formed at the grain boundaries. In this work, differences in the microstructure evolution during homogenization between a conventionally cast and a spray-formed 7055 alloy are investigated, including the dissolution of the primary phases and the precipitation behavior of the $\mathrm{Al}_{3} \mathrm{Zr}$ dispersoids. Subsequently, in order to analyze the influence of the dispersoids on the recrystallization resistance during post-deformation annealing, these two differently processed materials have been subjected to hot extrusion processing after the homogenization treatment.

\section{EXPERIMENTAL PROCEDURE}

\section{A. Material Processing}

To meet the requirements of this work, a direct-chill cast 7055 ingot was manufactured at the research lab of University of Science and Technology Beijing, while a spray-formed 7055 alloy billet was provided by Haoran Co., Ltd Jiangsu, China. The two types of fabrication processes have significant differences. The cast 7055 alloy was melted in a graphite crucible using an electrical resistance furnace. The melt was poured at a temperature of $750{ }^{\circ} \mathrm{C}$ into a rectangular permanent steel mold to produce a cast ingot with size of $\phi 100 \mathrm{~mm}$ in diameter and $70 \mathrm{~mm}$ in length. The spray deposition method combines the atomization and consolidation step into one operation, which results in a rapid solidification process. The spray deposition methodology is described in more detail elsewhere. ${ }^{[6]}$ Samples were cut from the rod ingots with sizes of $\phi 500 \mathrm{~mm}$ in diameter and 1600 $\mathrm{mm}$ in length, produced by a SFZD-5000 type fully automatic-controlled reciprocating spray forming equipment. The chemical composition of the two alloys considered is shown in Table I. Both alloys have the same zirconium content and almost the same content also of the other alloying elements.

\section{B. Heat Treatment and Thermo-Mechanical Processing}

For the experiments, $10 \times 10 \times 1$-mm sheet specimens and $\phi 80 \times 50-\mathrm{mm}$ cylindrical specimens were cut from ingots of both alloys. The same heat treatment temperatures and extrusion process parameters were applied to both the as-cast and the as-deposited alloy. The homogenization treatment was carried out at $350{ }^{\circ} \mathrm{C} / 5$ hours + $470{ }^{\circ} \mathrm{C} / 24$ hours with an initial heating rate of $30{ }^{\circ} \mathrm{C} /$ hour from room temperature in an air-circulating furnace. Following the homogenization heat treatment, sheet specimens used to analyze precipitation of dispersoids by scanning electron microscope were quenched into cold water which was to avoid the formation of additional second phases during cooling, while the cylindrical specimens applied to extrusion experiments were cooled in air (to imitate actual industrial processing conditions). Specimens with a diameter of $80 \mathrm{~mm}$ were extruded at $420{ }^{\circ} \mathrm{C}$ using an extrusion ratio of $25: 1$. The as-extruded materials were cooled in air. Specimens were cut from one quarter of the diameter of the extrusion rod, treated at $470{ }^{\circ} \mathrm{C}$ for 2,72 hours, respectively, in an air-circulating furnace, and waterquenched to room temperature.

\section{Microstructural Characterization}

The microstructure of the alloys was characterized by optical microscopy (OM), scanning electronic microscopy (SEM) (AURIGA, Zeiss), electron probe X-ray micro-analysis (EPMA), and transmission electron microscopy (TECNAI F20, ThermoFisher) operated at a nominal voltage of $200 \mathrm{keV}$. Metallographic examinations were carried out on samples both of the as-cast alloy and as-deposited alloy. Samples were etched by 
Table I. Chemical Composition of 7055 Aluminum Alloy (Weight Percent)

\begin{tabular}{lllllrrr}
\hline Elements & $\mathrm{Zn}$ & $\mathrm{Mg}$ & $\mathrm{Cu}$ & $\mathrm{Zr}$ & $\mathrm{Fe}$ & $\mathrm{Si}$ & $\mathrm{Al}$ \\
\hline Nominal Value & $7.6-8.4$ & $1.8-2.3$ & $2.0-2.6$ & $0.05-0.25$ & $\leq 0.15$ & $\leq 0.10$ & bal. \\
As-Cast & 8.22 & 2.12 & 2.41 & 0.12 & 0.04 & 0.004 & bal. \\
As-Deposited & 8.25 & 2.09 & 2.51 & 0.12 & 0.05 & 0.03 & bal. \\
\hline
\end{tabular}

Keller's reagent after grinding with SiC-based emery paper and polished with diamond-polishing paste. The compositional distribution of solute elements in both alloys was investigated by an Electron Probe Micro Analyzer (EPMA). The composition of the second-phase particles of the two alloys and distribution of the dispersoids were analyzed by a SEM equipped with an energy-dispersive spectrometer detector (EDS) and back-scattered electron detector (BSE). TEM specimens of the heat-treated as-cast 7055 alloy and the as-extruded materials of two 7055 alloys after heat treatment at $470{ }^{\circ} \mathrm{C}$ for 2 hours were prepared by cutting discs from the selected samples and thinning the discs mechanically to $50 \mu \mathrm{m}$ before they were twin-jet electropolished in a mixture of 30 pct nitric acid and 70 pct methanol at a temperature of $-30{ }^{\circ} \mathrm{C}$ with a working voltage of $15 \mathrm{~V}$. The TEM specimens of the heat-treated as-deposited 7055 alloys were prepared by using focused-ion beam (FIB) thinning.

Furthermore, specimens for Electron Backscattering Diffraction (EBSD), which paralleled to the extrusion direction (ED) to the transverse direction (TD), were prepared by standard mechanical grinding and electrolytic polishing, and then examined by electron back-scattered diffraction (EBSD) in the SEM. And the microstructures were analyzed by HKL Channel5 software.

\section{RESULTS}

A. Microstructure of the As-Cast and As-Deposited 7055 Alloys

Figure 1 presents typical optical micrographs and SEM BSE micrographs images of the as-cast and the as-deposited 7055 alloy. Different grain structures can be clearly seen in Figures 1(a) and (b). Ten micrographs were analyzed by the linear-intercept method to provide an average grain size. The results show that the grain size of the as-cast and as-deposited 7055 alloys was $85 \pm$ 30 and $42 \pm 15 \mu \mathrm{m}$ in diameter, respectively. In addition, intermetallic constituent particles and typical eutectic structures were observed at the grain boundaries in Figures 1(c) and (d). While coarse and reticulated eutectic phases are observed in the as-cast 7055 alloy, no such phases are observed in as-deposited 7055 alloy. Near the grain boundaries in the as-cast 7055 alloy, many fine particles are observed; this is the $\eta\left(\mathrm{MgZn}_{2}\right)$ phase which precipitated out during the cooling stage after solidification following solute segregation towards the grain boundaries and their periphery, while larger second-phase particles within the grains were formed during the spray deposition process in the as-deposited 7055 alloy.

Figure 2 shows SEM BSE micrographs and corresponding EDS-derived composition maps of the as-cast and the as-deposited 7055 alloy. In the latter, many large second-phase particles distributed along grain boundaries are observed. Most of the second-phase particles show up as white phases in Figure 2(a), while some gray phases embedded in the white phases are observed in Figure 2(b). Many studies have documented that the white phase in Figure 2 is the $\mathrm{Mg}(\mathrm{Zn}, \mathrm{Cu}, \mathrm{Al})_{2}$ phase, which has a similar structure as $\mathrm{MgZn}_{2}$ containing $\mathrm{Al}$ and $\mathrm{Cu}$, while the gray phase in Figure 2(b) (as-cast) is the $\mathrm{Al}_{2} \mathrm{CuMg}$ phase. ${ }^{[12,13]}$ However, no such $\mathrm{Al}_{2} \mathrm{CuMg}$ phase embedded in the coarse $\mathrm{Mg}(\mathrm{Zn}, \mathrm{Cu}, \mathrm{Al})_{2}$ phase is observed in the as-deposited 7055 alloy.

Figures 3(a) and (b) show SEM BSE micrographs with typical grain structures, from which EPMA analyses of composition were carried out along the marked lines indicated in Figures 3(a) and (b), respectively. In Figures 3(c) and (d), the distinct peaks of $\mathrm{Zn}, \mathrm{Mg}$, and $\mathrm{Cu}$ correspond to the position of the second-phase particles. Moreover, from Figure 3(d), segregation of zirconium is observed in the as-cast 7055 alloy, which means that in regions without segregations, zirconium levels are below the nominal value. Slow cooling rate and a dendritic structure are important factors for zirconium segregation in a traditional cast 7055 alloy. Figure 3(c), on the other hand, shows a uniform distribution of zirconium in the as-deposited 7055 alloy, owing to the rapid cooling process of spray forming.

\section{B. Precipitation Behavior of $\mathrm{Al}_{3} \mathrm{Zr}$ Dispersoid During Homogenization}

To make comparisons after the homogenization heat treatment of these two alloys, the distribution of $\mathrm{Al}_{3} \mathrm{Zr}$ dispersoids across one whole grain was investigated. Figure 4 shows the distribution of $\mathrm{Al}_{3} \mathrm{Zr}$ dispersoids in a typical grain after homogenization heating at $350{ }^{\circ} \mathrm{C} / 5$ hours $+470{ }^{\circ} \mathrm{C} / 24$ hours observed by SEM BSE imaging. It is observed from Figure 4(b) that the as-cast 7055 alloy results in an inhomogeneous distribution of $\mathrm{Al}_{3} \mathrm{Zr}$ dispersoids within a grain. At the same time, it is found from Figure 4(a) that the $\mathrm{Al}_{3} \mathrm{Zr}$ dispersoids are more homogeneously distributed within a grain in the as-deposited 7055 alloy. High-magnification BSE micrographs of the dispersoids near the grain boundary are shown in Figure 5. Close to the grain boundary, precipitation-free zones (PFZ) are observed both in Figures 5(a) and (b), in which the PFZ in the spray-formed 7055 alloy is quite distinct, while a 


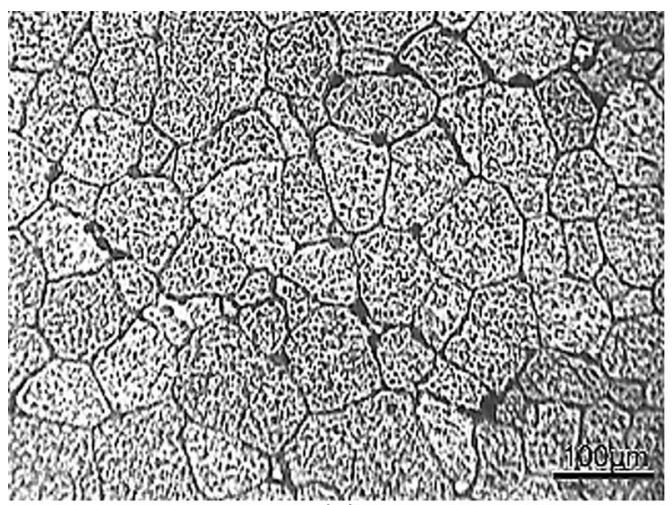

(a)

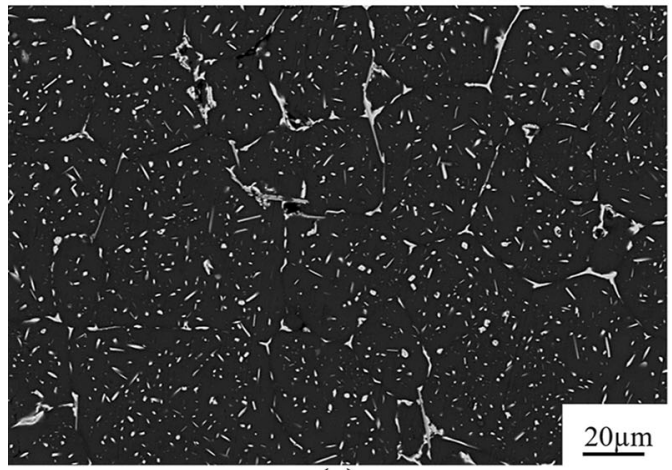

(c)

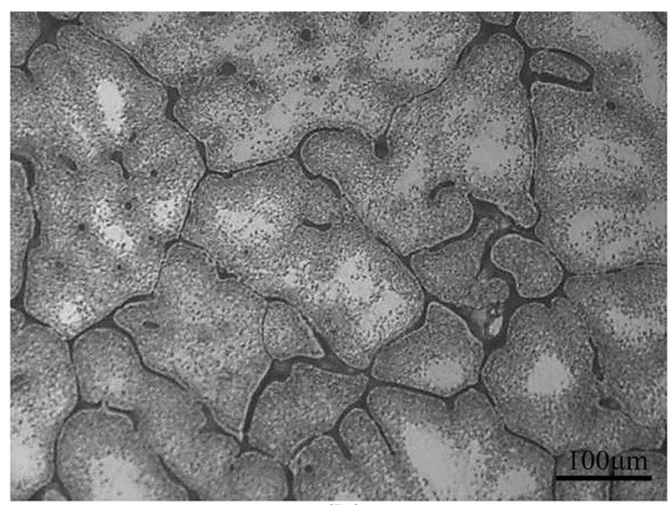

(b)

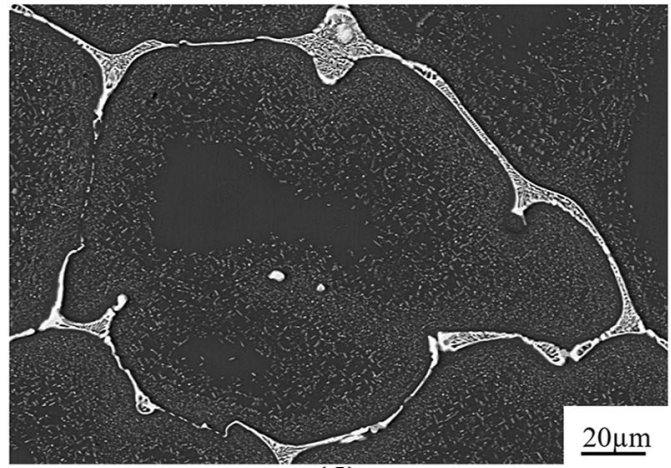

(d)

Fig. 1-Typical optical images and backscattered SEM BSE micrographs of 7055 alloy ingots: (a) (c) as-deposited, (b) (d) as-cast.

transition region with a small number density of $\mathrm{Al}_{3} \mathrm{Zr}$ dispersoids is observed in the conventionally cast 7055 alloy.

These differences are even more clear in typical TEM dark-field images of the $\mathrm{Al}_{3} \mathrm{Zr}$ dispersoid distribution near grain boundary regions after homogenization, as presented in Figure 6, which were taken along the [001] zone axis of the $\mathrm{Al}$ matrix with two-beam diffraction conditions. According to the selected area diffraction (SAD) pattern shown in the inset of Figure 6(a), it can be derived that the structure of the $\mathrm{Al}_{3} \mathrm{Zr}$ precipitates is consistent with the $\mathrm{L}_{2}$ crystal structure. With reference to Figures 6(a) and (b), it can be observed that the closer to the grain boundary, the larger the size of the $\mathrm{Al}_{3} \mathrm{Zr}$ dispersoids is. Nevertheless, compared with the conventionally cast 7055 alloy, a higher number density of $\mathrm{Al}_{3} \mathrm{Zr}$ dispersoids adjacent to the grain boundary are obtained for the spray-formed 7055 alloy. In the as-cast variant there is a tendency that several $\mathrm{Al}_{3} \mathrm{Zr}$ dispersoids group into elongated clusters as observed in in Figure 6(b), while this is not the case in the as-deposited variant (Figure 6(a)).

In general, Figure 6 can be divided into three regions (i.e., I, II, and III, with I being closest to the grain boundary) showing different precipitation behavior in both alloys. Figure 7 shows the average radius of the $\mathrm{Al}_{3} \mathrm{Zr}$ dispersoids in the three regions. It can be observed that the $\mathrm{Al}_{3} \mathrm{Zr}$ dispersoids in region I have the largest average radius, and that the average radius of $\mathrm{Al}_{3} \mathrm{Zr}$ of the conventionally cast 7055 alloy is distinctly larger than that of the spray-formed 7055 alloy in regions I and II, while the average size of the $\mathrm{Al}_{3} \mathrm{Zr}$ dispersoids are almost the same in region III. Most importantly, compared with the conventionally cast 7055 alloy, the average radius of the $\mathrm{Al}_{3} \mathrm{Zr}$ dispersoids in the sprayformed 7055 alloy varies little from grain center to grain boundary. So, unevenly distributed zirconium not only causes different distributions of $\mathrm{Al}_{3} \mathrm{Zr}$, but also significantly affects particle size. The average radius of the $\mathrm{Al}_{3} \mathrm{Zr}$ in the single grain of the spray-formed 7055 alloy and the traditional cast 7055 alloy is 19.1 and $21.7 \mathrm{~nm}$ respectively, which is based on analyses (counting) of ten TEM micrographs with the Image $\mathbf{J}$ software.

\section{Effect of $\mathrm{Al}_{3} \mathrm{Zr}$ dispersoids on recrystallization resistance}

To study the recrystallization behavior of the as-cast and as-deposited 7055 alloys, in near industrial conditions, homogenized and air-cooled materials were first extruded, which resulted in a fibrous non-recrystallized grain structure, and then subjected to a post-deformation heat treatment, i.e., the as-extruded samples were annealed at $470{ }^{\circ} \mathrm{C}$ for 2 and 72 hours, respectively, and subsequently quenched in water at ambient temperature.

SEM BSE micrographs of the as-extruded 7055 alloys are shown in Figure 8. Some large-sized residual phases and a large amount of small-sized phases precipitated 

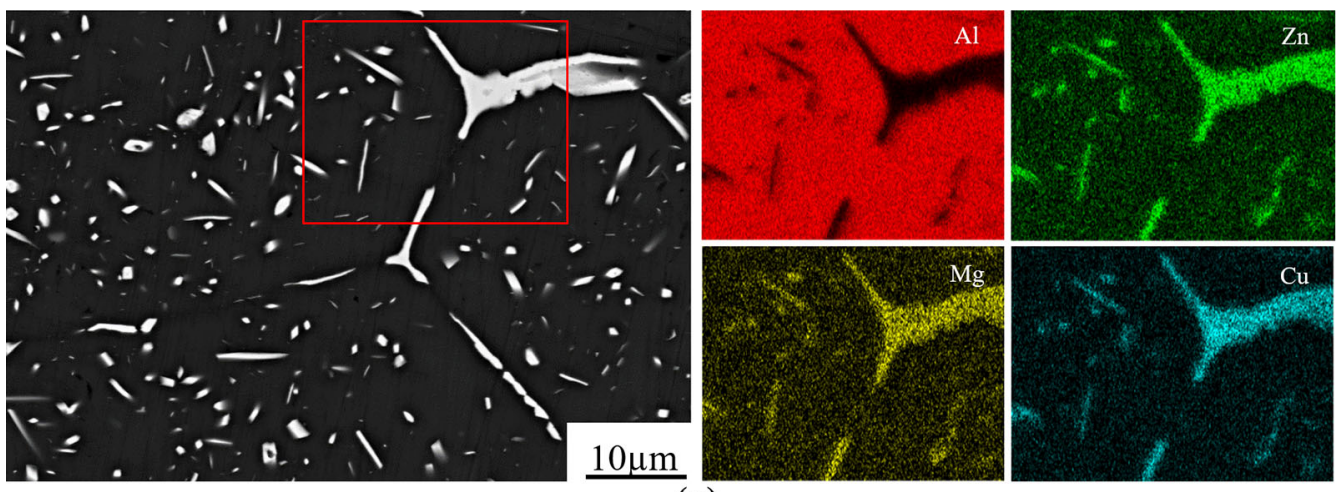

(a)
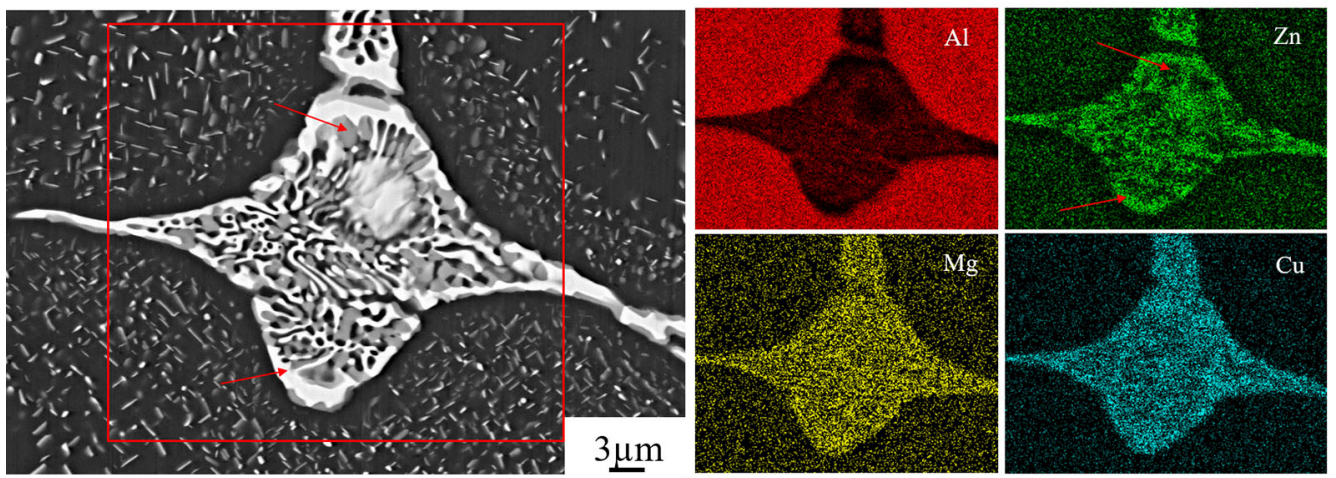

(b)

Fig. 2-SEM BSE micrographs and corresponding EDS-derived composition maps for $\mathrm{Al}, \mathrm{Zn}, \mathrm{Mg}$, and $\mathrm{Cu}$ of 7055 alloy ingots: (a) as-deposited, (b) as-cast.

during air cooling after homogenization are observed. Moreover, it can be seen that there are no obvious differences between the spray-formed 7055 alloy and the conventionally cast 7055 alloy with respect to the second-phase particles in size and number density.

Meanwhile, when the degree of deformation is large, obvious differences in the original grain size before deformation become negligible after deformation. So, the effect of the different original grain size and second phases on the recrystallization behavior can be ruled out for this study.

It should be emphasized the second-phase particles shown in Figure 8 come in addition to the $\mathrm{Al}_{3} \mathrm{Zr}$ dispersoids formed during homogenization, resulting from the slow cooling after homogenization of the extruded variants. This is presumingly mainly $\mathrm{MgZn}_{2}$ containing $\mathrm{Al}$ and $\mathrm{Cu}$ particles, which are generally much larger in size than the $\mathrm{Al}_{3} \mathrm{Zr}$ dispersoids. At the same time, it is reasonable to assume that the $\mathrm{Al}_{3} \mathrm{Zr}$ dispersoids are not affected by the differences in cooling after homogenization (except for a possible slight coarsening and that they are stable during the subsequent extrusion process). Thus, their presence in terms of number densities, size, and distributions is therefore expected to be similar in the as-extruded conditions and that the distinct differences between the as-cast alloy and the as-deposited, as discussed in the previous section are retained.
This is supported by detailed TEM investigations of the near grain boundary regions of the as-extruded materials. Figure 9 shows typical TEM bright-field images of the as-extruded 7055 alloy in grain boundary regions after annealing at $470{ }^{\circ} \mathrm{C}$ for 2 hour. It is clearly observed that the $\mathrm{Al}_{3} \mathrm{Zr}$ dispersoids on or near grain boundary are more numerous in the spray-formed 7055 alloy in Figure 9(a) than in the conventionally cast 7055 alloy in Figure 9(b). It should be noted that the same behavior was observed from several different grain boundaries in two TEM samples of the two alloys. Thus, from these observations it is expected that the overall recrystallization resistance of the spray-formed 7055 alloy is better than that for the conventionally cast 7055 alloy due to the $\mathrm{Al}_{3} \mathrm{Zr}$ dispersoids exerting a retarding force or pressure on grain boundary movement.

Figure 10, in the form of SEM EBSD orientation imaging maps, shows the influence of the presence and distribution of $\mathrm{Al}_{3} \mathrm{Zr}$ on the recrystallization behavior of the two 7055 alloys after long annealing time at $470{ }^{\circ} \mathrm{C}$ for 72 hours. Figure 10(a), referring to the spray-formed 7055 alloy, shows a recovered, but still mainly deformed, fibrous microstructure with limited recrystallized grains, while a mainly recrystallized microstructure can be easily found in some area of the conventionally cast 7055 alloy in Figure 10(b), although also large regions in this sample still present mainly a deformed 


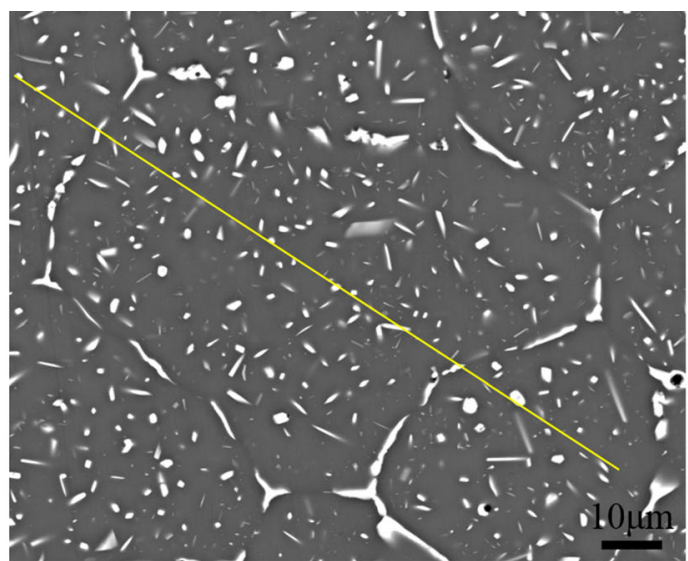

(a)

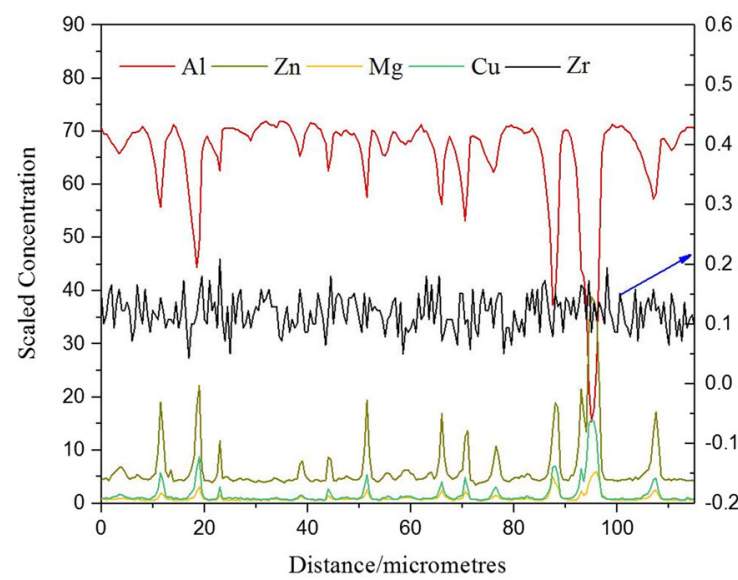

(c)

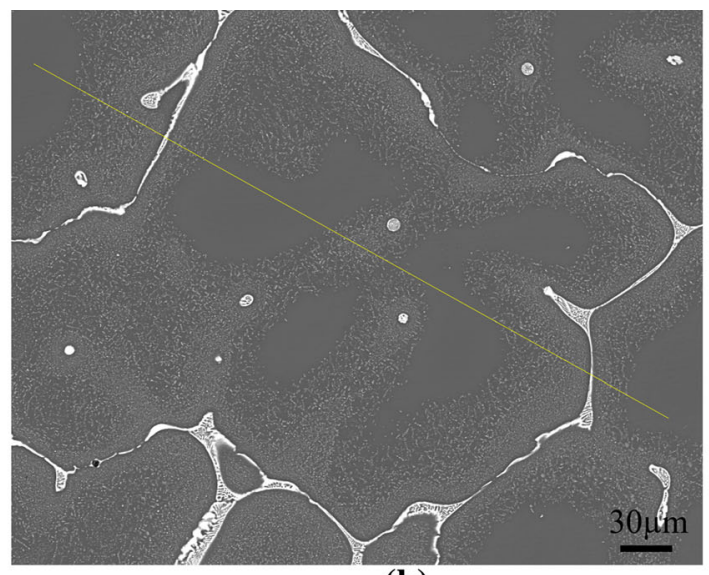

(b)

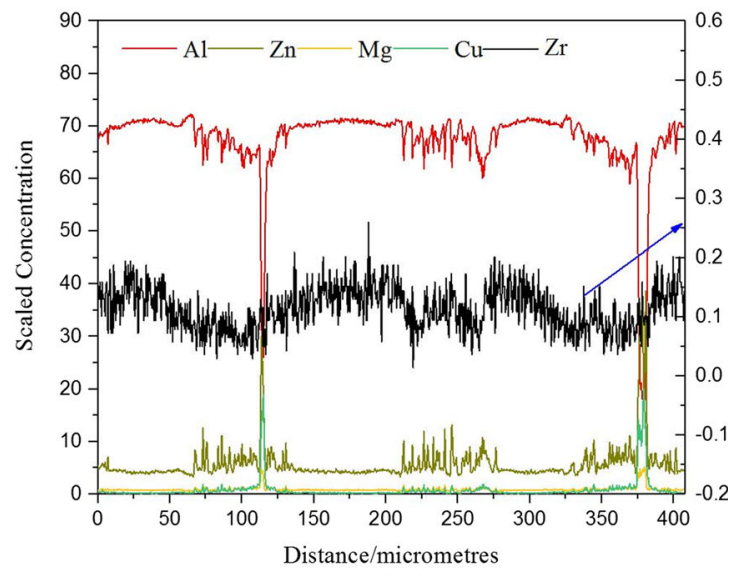

(d)

Fig. 3-SEM BSE micrographs $(a, b)$ images and corresponding line scanning analysis $(c, d)$ of 7055 alloy ingots from EPMA: $(a)(c)$ as-deposited, $(b)(d)$ as-cast.
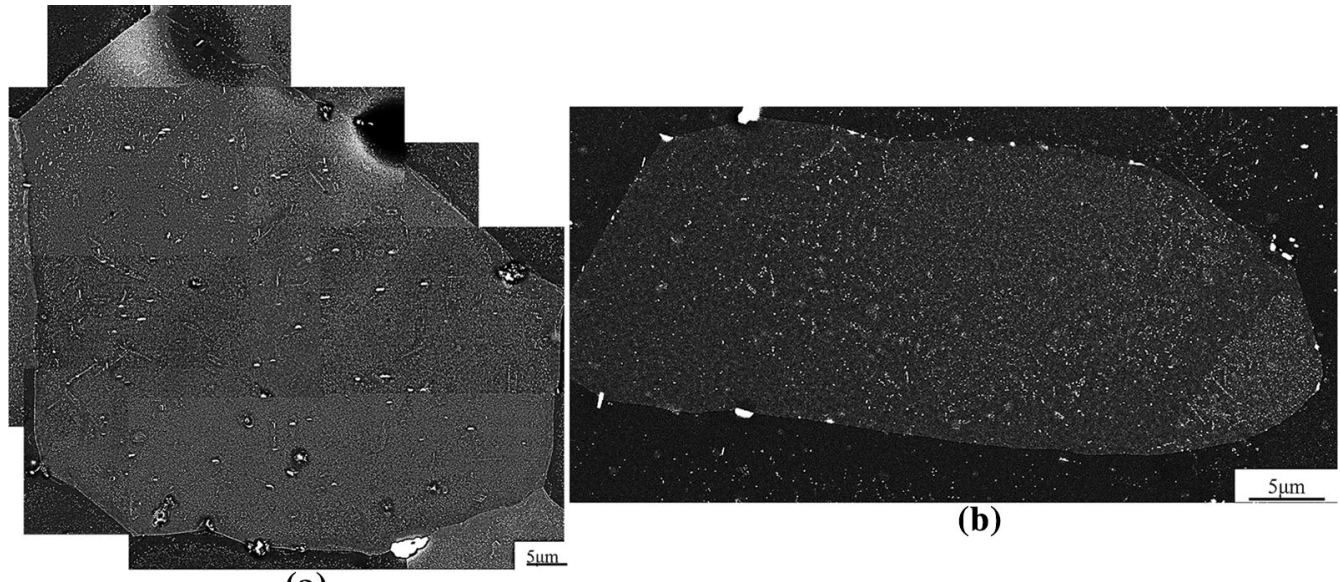

(a)

Fig. 4 - SEM BSE micrographs of a single grain showing a typical distribution of dispersoids after homogenization at $350{ }^{\circ} \mathrm{C} / 5 \mathrm{~h}+470{ }^{\circ} \mathrm{C} / 24 \mathrm{~h}$, (a) spray-formed 7055 alloy, (b) conventionally cast 7055 alloy. 


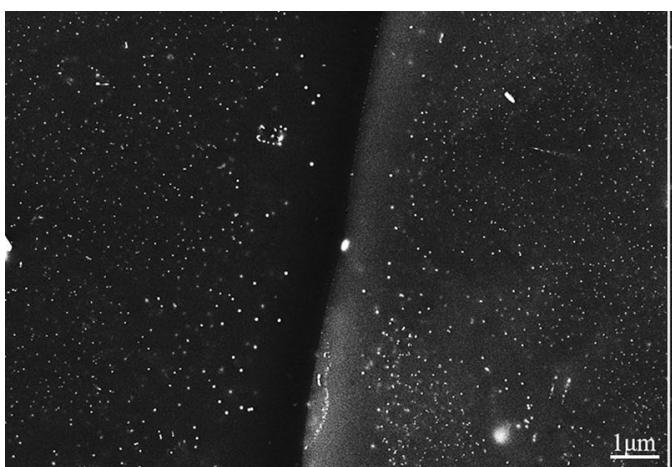

(a)

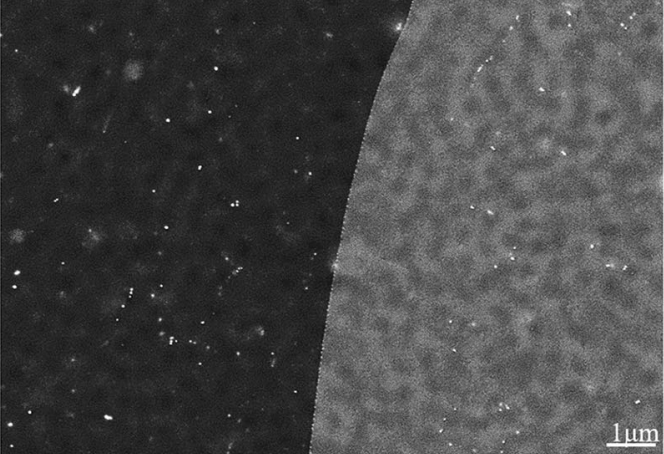

(b)

Fig. 5-High-magnification SEM BSE micrographs of the grain boundary region after homogenization: (a) spray-formed 7055 alloy, (b) conventionally cast 7055 alloy.

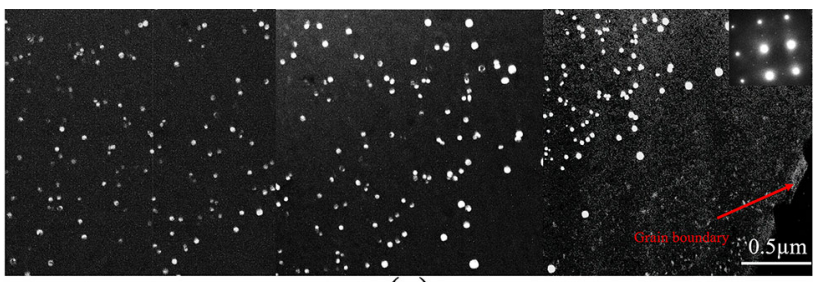

(a)

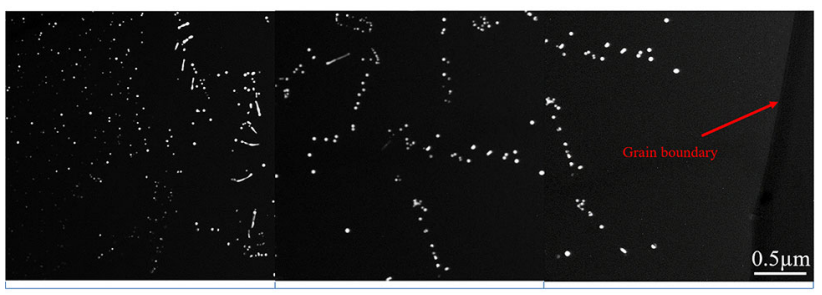

(b)

Fig. 6-Typical TEM dark-field images of $\mathrm{Al}_{3} \mathrm{Zr}$ dispersoids distribution in grain boundary regions after homogenization: (a) spray-formed 7055 alloy, (b) conventionally cast 7055 alloy.

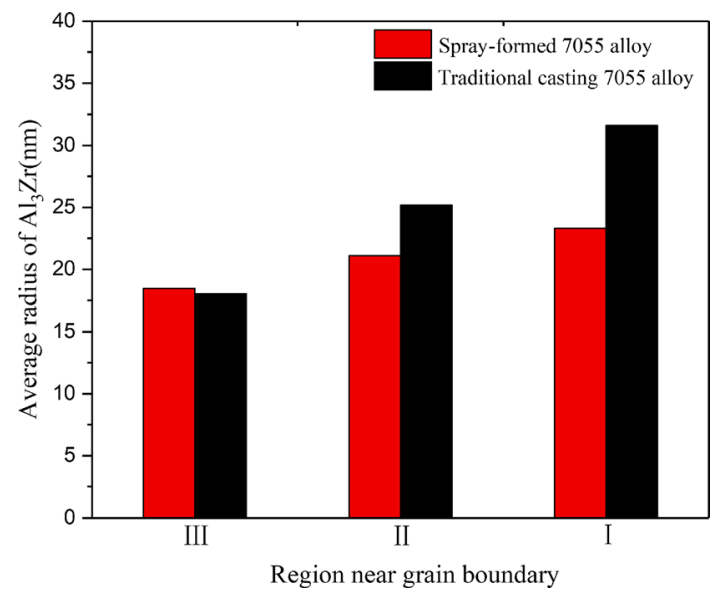

Fig. 7-Three regions average radius of $\mathrm{Al}_{3} \mathrm{Zr}$ dispersoids near grain boundary of 7055 alloy after homogenization treatments. microstructure. This difference is definitely attributed to the variation of the $\mathrm{Al}_{3} \mathrm{Zr}$ dispersoids in the two alloys.

\section{DISCUSSION}

Compared with the conventionally cast 7055 alloy, the microstructure of the spray-formed 7055 alloy has been largely changed due to the rapid solidification in the process of spray deposition. Figure 1 shows that the as-deposited 7055 alloy is composed of smaller equiaxed grains, some fine second-phase particles distributed in grain and smaller eutectic phases distributed on grain boundaries as compared to the as-cast 7055 alloy. The as-cast 7055 alloy on the other hand comprises coarse dendrites and larger networked eutectic phases. Besides, the type of phases is also different. Figure 2 illustrates that there is no $\mathrm{Al}_{2} \mathrm{CuMg}$ phase that are embedded in the coarse $\mathrm{Mg}(\mathrm{Zn}, \mathrm{Cu}, \mathrm{Al})_{2}$ phase of the grain boundary distribution in the as-deposited 7055 alloy. The change in microstructure of the as-deposited 7055 alloy is mainly due to the unique spray deposition process. During spray deposition, the majority of atomized droplets maintain partially solidified at the flight process, then gradually accumulate and form a semi-liquid layer on top of the billet and finally obtain a large amount of broken dendrite fragments. Afterwards, these dendrite fragments act as solidification nuclei. As the temperature decreases, the nuclei grow and merge with each other at the interface, developing to the morphology of the equiaxed grains. ${ }^{[11]}$

In addition, the composition distribution has also been changed in as-deposited 7055 alloy, compared to the as-cast 7055 alloy. Figure 3 clearly shows the segregation of zirconium in the as-cast 7055 alloy, but which is not taking place in the as-deposited 7055 alloy. It is well known that the solidification of conventionally cast 7055 alloy is accompanied by varying degrees of micro-segregation of alloying elements due to their partitioning between liquid and solid phases during solidification, and due to the non-equilibrium dendritic solidification. ${ }^{[12]}$ The spray forming technology can 


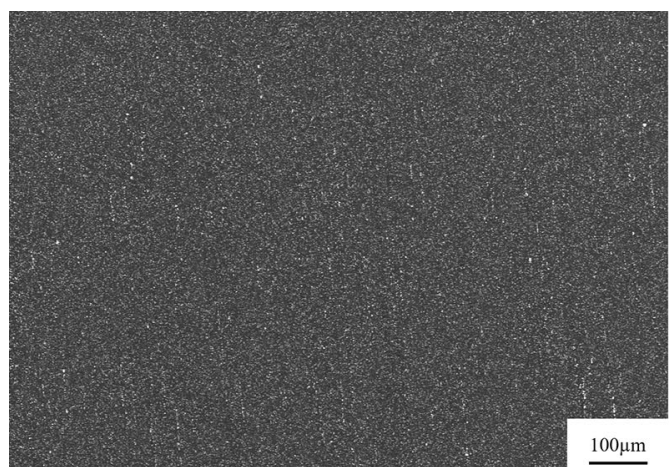

(a)

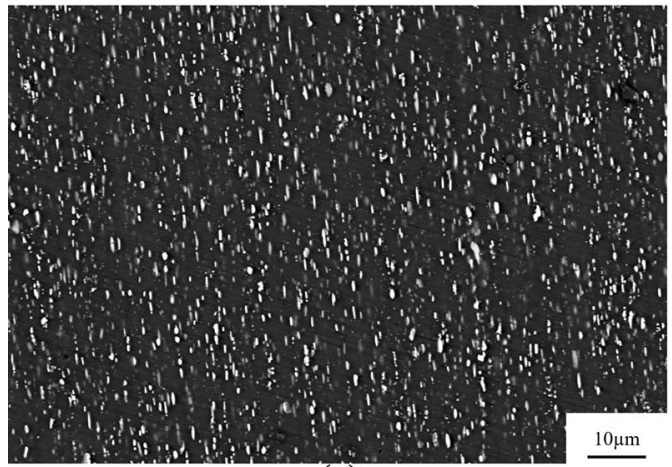

(c)

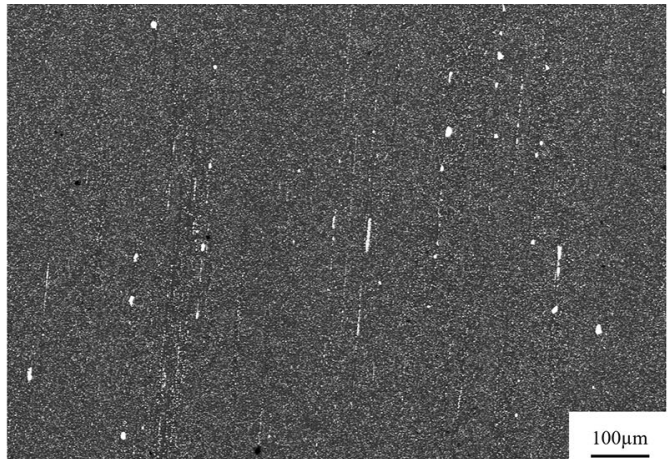

(b)

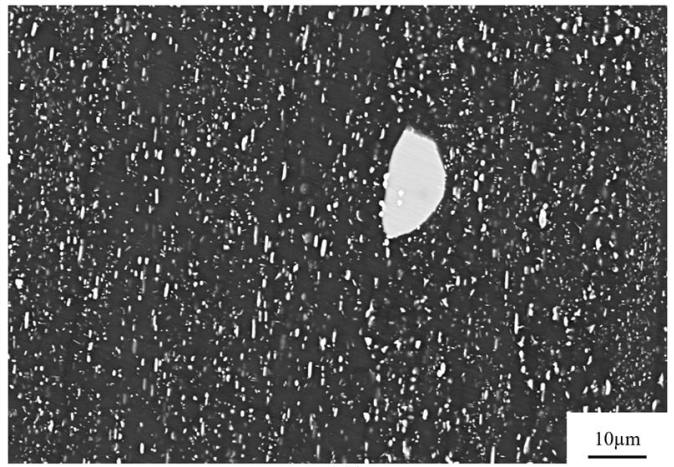

(d)

Fig. 8-BSE micrographs and the corresponding enlarged map of as-extruded 7055 alloys: $(a)(c)$ spray-formed 7055 alloy, $(b)(d)$ conventionally cast 7055 alloy.

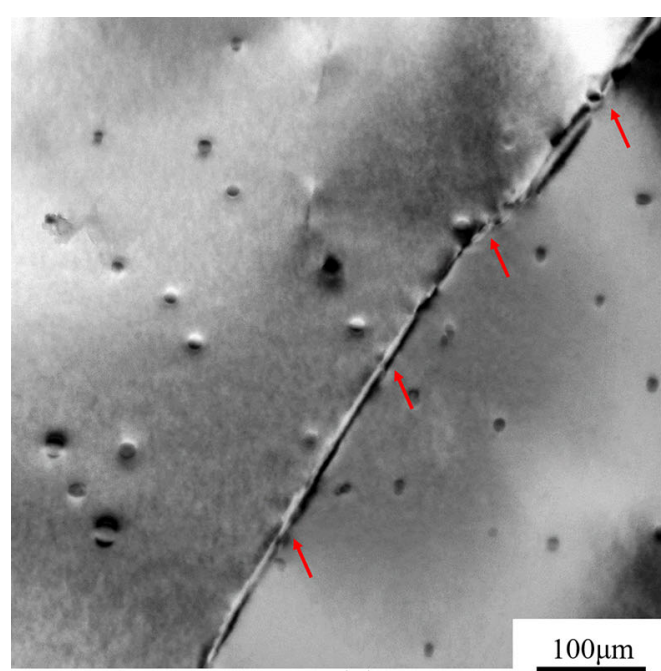

(a)

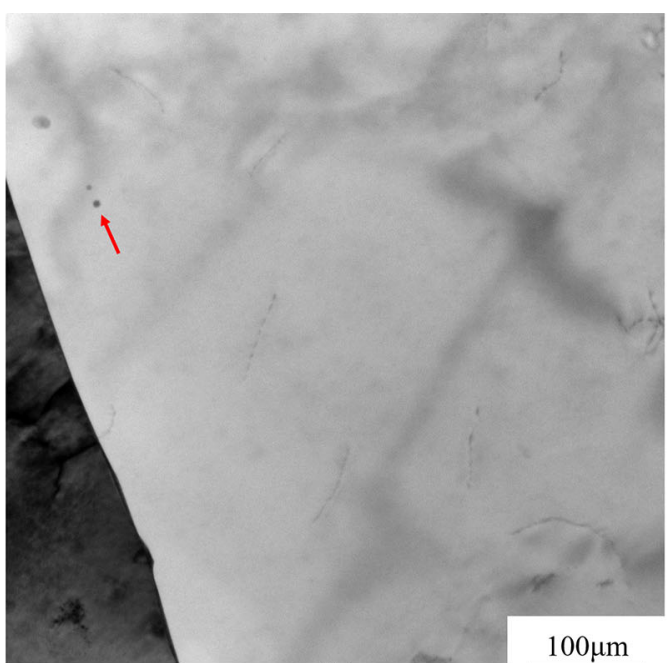

(b)

Fig. 9-TEM bright-field images of the as-extruded 7055 alloy in grain boundary regions after annealing at $470{ }^{\circ} \mathrm{C}$ for 2 h: $(a)$ spray-formed 7055 alloy, (b) conventionally cast 7055 alloy.

effectively avoid this phenomenon due to the rapid solidification and without a characteristic dendritic structure. In general, because of this special forming process, the type, size and distribution of primary phases, the composition, and the grain structure are changed in the spray-formed 7055 alloy. Thus, the effect of heat treatment, such as homogenization, on evolution of microstructure and precipitation of dispersoids is also significantly different for the spray-formed 7055 alloy as compared to the conventionally cast alloy.

It is well known that one of the main functions of a homogenization heat treatment is to eliminate micro-segregations and internal stresses in the as-cast alloys. In Zr-containing alloys, like 7055, a significant 


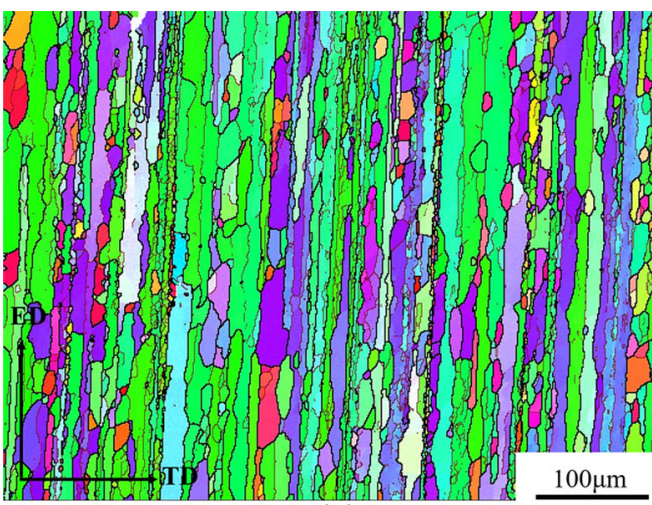

(a)

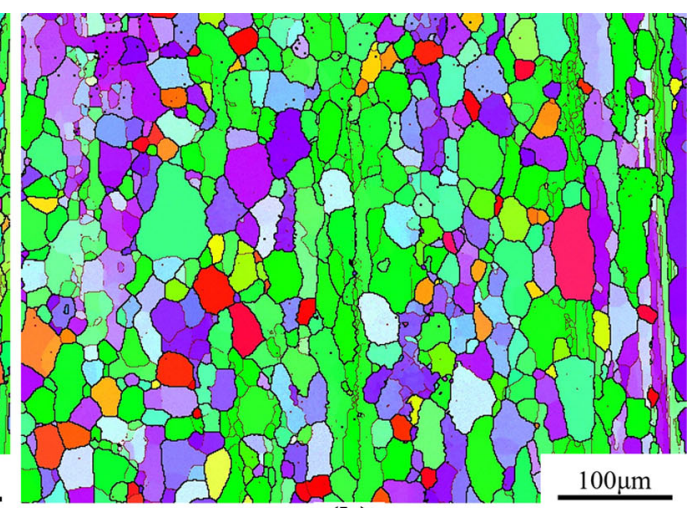

(b)

Fig. 10 - SEM EBSD orientation imaging maps of 7055 alloy after annealing at $470{ }^{\circ} \mathrm{C} / 72 \mathrm{~h}$ : $(a)$ spray-formed 7055 alloy, (b) conventionally cast 7055 alloy.

amount of thermally stable, coherent $\mathrm{Al}_{3} \mathrm{Zr}$ dispersoids can also be precipitated during homogenization, which potentially may have a significant effect on suppressing recrystallization. ${ }^{[14]}$ Although there are no micro-segregations in the as-deposited 7055 alloy, homogenization is also indispensable for the spray-formed 7055 alloy, as the $\mathrm{Al}_{3} \mathrm{Zr}$ dispersoids formed during homogenization are crucial for optimizing the mechanical properties of the alloy. It is evident that the distribution of zirconium in the alloy has an essential influence on the precipitation of $\mathrm{Al}_{3} \mathrm{Zr}$. There are a lot of studies showing that zirconium segregations are commonly observed in conventionally cast $\mathrm{Zr}$-containing $\mathrm{Al}$ alloys, and the compositional variations of zirconium are closely related to dendritic structure. It can be seen from Figure 3 that zirconium segregations are also found in the as-cast 7055 alloy investigated in this work, while zirconium is more uniformly distributed in the as-deposited 7055 alloy. In general, the zirconium concentration often exceeds its nominal value close to the center of the dendrite arms since these regions solidified first during casting. Thus, zirconium levels near the grain boundaries and interdendritic regions are inevitably lower than average. However, the spray forming process prevents the appearance of a dendritic structure and the rapid solidification process makes the alloying elements distribute more uniformly through the whole grain in the as-deposited 7055 alloy. Thus, the degree of supersaturation of zirconium across grains is also quite different between these two alloys. Since the $\mathrm{Al}_{3} \mathrm{Zr}$ dispersoids are precipitating directly from the as-cast state and as-deposited state and driving force for precipitation of $\mathrm{Al}_{3} \mathrm{Zr}$ is strongly linked with the supersaturation of zirconium, obviously different precipitation behavior will be found between these two alloys during homogenization.

Experimental observations from Figure $4 \mathrm{~b}$ clearly demonstrate that the segregation of zirconium in the as-cast 7055 alloy leads to a varying distribution of $\mathrm{Al}_{3} \mathrm{Zr}$ dispersoids within each grain. The density variation of the $\mathrm{Al}_{3} \mathrm{Zr}$ dispersoids is owed to the local in-grain zirconium segregations during solidification. With an increasing zirconium content, the supersaturation increases so that the driving force for nucleation also increases, leading to the formation of a larger number of dispersoid particles. However, the process of forming new $\mathrm{Al}_{3} \mathrm{Zr}$ particles is a competition for the available solute between nucleation and growth of already existing dispersoids. Figures 6(b) and 7 show the variation in dispersoid size and number density from the grain boundary to the center of the grain in the conventionally cast 7055 alloy. It can be seen that the $\mathrm{Al}_{3} \mathrm{Zr}$ number density increases and mean radius decreases in the zirconium segregation zone (grain center). As the nucleation rate is large and many particles form, $\mathrm{Al}_{3} \mathrm{Zr}$ dispersoids can only grow to a limited degree before all the available supersaturated zirconium in solid solution are consumed. On the contrary, the nucleation rate is presumably lower than the growth rate in areas with low zirconium concentration, resulting in the formation of fewer $\mathrm{Al}_{3} \mathrm{Zr}$ dispersoids, while each of them can grow to a larger size before depleting the Al matrix of supersaturated zirconium. However, compared with the conventionally cast 7055 alloy, the precipitation behavior of the $\mathrm{Al}_{3} \mathrm{Zr}$ dispersoids in spray-formed 7055 alloy is distinctively different during the homogenization. Figure 4(a) shows that an important consequence of the uniform distribution of zirconium in the as-deposited 7055 alloy is that $\mathrm{Al}_{3} \mathrm{Zr}$ dispersoids also distribute more evenly in each grain. Due to the uniform distribution of zirconium concentration, i.e., a similar supersaturation at each position in the grain, it can be assumed that the nucleation rate and growth rate of the dispersoids are also the same throughout the whole grain, and as demonstrated from Figures 6(a) and 7, there are no significant differences in dispersoid size and number density from the grain center to the boundary in the spray-formed 7055 alloy.

Dispersoid-free regions, or regions of low number density, are likely to recrystallize most easily during heat treatment. It can be clearly observed from Figures 5 and 6 that dispersoid-free regions are present in both of these 
7055 alloys. However, while more distinct narrow in the spray-formed alloy, a wider transition region with a small number of $\mathrm{Al}_{3} \mathrm{Zr}$ dispersoids with a relatively large mean radius is observed in the conventionally cast 7055 alloy. In general, it is important for cast alloys to minimize the width of these regions as it may have a detrimental effect on the recrystallization resistance and thus lead to a larger fraction of recrystallization. These regions usually appear at the dendrite edges. As the zirconium concentration falls, the number density of $\mathrm{Al}_{3} \mathrm{Zr}$ dispersoids decreases and the mean radius increases, leading to a narrow band of large $\mathrm{Al}_{3} \mathrm{Zr}$ dispersoids. When zirconium concentration is further reduced towards the grain boundary, the number density of $\mathrm{Al}_{3} \mathrm{Zr}$ dispersoids may fall almost to zero, corresponding to a dispersoid-free region. Similarly, there are also dispersoid-free regions in the spray-formed 7055 alloy, but there is no transition region with a narrow band of large $\mathrm{Al}_{3} \mathrm{Zr}$ dispersoids because of the more evenly distribution of zirconium resulting from the absence of a dendritic structure. Accordingly, there is a significant difference in size and distribution of $\mathrm{Al}_{3} \mathrm{Zr}$ dispersoids between these two 7055 alloys, and the grain structure is influenced during the subsequent heat treatment, during their effect on the recrystallization behavior.

The two 7055 alloys contain several types phases (particle populations) in the as-extruded state, which may have different influences on the recrystallization behavior. For example, it can be seen from Figure 8 that a large number of near micrometer-sized second-phase particles are precipitated during the air cooling after homogenization, which potentially may act as nucleation sites for recrystallization through the accumulated stored energy in their immediate vicinity, and hence being potent nucleation sites for recrystallization (i.e., particle-stimulated nucleation (PSN) of recrystallization). ${ }^{[21-24]}$ However, the effect of these second-phase particles for possible differences in the recrystallization behavior can be ignored in this study because there is no obvious difference between these two alloys with respect to the size and number density of these second-phase particles. Moreover, the particles size of almost all of the second-phase particles in Figure 8 is less than $1 \mu \mathrm{m}$. Thus the effect of particle stimulated nucleation of recrystallization (PSN) on the alloy during annealing is presumably weak, as the condition for PSN is typical that the particle diameter should be greater than $\sim 1$ $\mu \mathrm{m} .{ }^{[21,22]}$ Therefore, to study the effect of $\mathrm{Al}_{3} \mathrm{Zr}$ on the recrystallization behavior of the two 7055 alloys in this work, long annealing time up to 72 hours at $470{ }^{\circ} \mathrm{C}$ is required during post-deformation heat treatments.

Both alloys in Figure 10 are partially recrystallized after annealing, but it is obvious that the recrystallized fraction of the spray-formed 7055 alloy is lower than the conventionally cast 7055 alloy. It is well accepted that a uniform fine distribution of dispersoids (in our case $\mathrm{Al}_{3} \mathrm{Zr}$ ) precipitated during homogenization can strongly suppress/retard and even prevent recrystallization during heat treatment of deformed alloys. ${ }^{[22,25,26]}$ The reason is that a fine dispersion of particles will exert a retarding force or pressure on grain boundary movement, and this may have a profound effect on the processes of recovery, recrystallization, and grain growth, known as the Zener pinning effect. The Zener pinning pressure $\left(\boldsymbol{P}_{\boldsymbol{Z}}\right)$ is related to the volume fraction of the particles $\left(\boldsymbol{F}_{\mathbf{V}}\right)$, their radius, and their boundary energy $(y)$ through the following well-known Eq. [1]. ${ }^{[27,28]}$

$$
P_{Z}=\frac{3 F_{V \gamma}}{2 r}
$$

Equation [1] shows that a uniform fine distribution of $\mathrm{Al}_{3} \mathrm{Zr}$ dispersoids can maximize the resistance to recrystallization because smaller $\boldsymbol{r}$ and larger $\boldsymbol{F}_{\mathbf{V}}$ provide a higher Zener pinning pressure to prevent the migration of grain boundaries. Given the more uniform distribution of $\mathrm{Al}_{3} \mathrm{Zr}$ dispersoids in the spray-formed 7055 alloy, the recrystallization resistance is expected to be more efficient in this alloy than the conventionally cast alloy. In the latter the volume fraction of $\mathrm{Al}_{3} \mathrm{Zr}$ particles $\left(\boldsymbol{F}_{\mathbf{V}}\right)$ is very low in most areas outside the $\mathrm{Al}_{3} \mathrm{Zr}$ segregation zone as shown in Figure 9(b) resulting in a Zener pinning pressure $\left(\boldsymbol{P}_{\mathbf{Z}}\right)$, expected to be too small in these regions to effectively suppress recrystallization.

\section{CONCLUSIONS}

The effect of different fabricating processes and homogenization on microstructure of 7055 alloy was investigated together with the recrystallization resistance of the two alloys upon post-extrusion annealing. The conclusions are summarized as follows:

(1) The average grain size of as-deposited 7055 alloy is about half the size of that of the as-cast 7055 alloy, and there is no $\mathrm{Al}_{2} \mathrm{CuMg}$ phase embedded in the coarse $\mathrm{Mg}(\mathrm{Zn}, \mathrm{Cu}, \mathrm{Al})_{2}$ phase distributed along the boundary distribution in as-deposited 7055 alloy. Significant micro-segregations of zirconium (with-in grains) are observed in the as-cast 7055 alloy, while any segregation of zirconium is mainly absent in in the as-deposited 7055 alloy.

(2) After homogenization heating at $350{ }^{\circ} \mathrm{C} / 5$ hours $+470{ }^{\circ} \mathrm{C} / 24$ hours, an inhomogeneous distribution of $\mathrm{Al}_{3} \mathrm{Zr}$ dispersoids within grains is observed in the conventionally traditional cast 7055 alloy, while the dispersoids are more homogeneously distributed in the spray-formed 7055 alloy.

(3) Compared with the conventionally cast 7055 alloy, the uniform distribution of $\mathrm{Al}_{3} \mathrm{Zr}$ dispersoids in the spray-formed 7055 alloy, more effectively (and uniformly) suppress recrystallization in this variant.

\section{ACKNOWLEDGMENTS}

This work was supported by the National Natural Science Foundation of China (Grant No. 51871035), the Fundamental Research Funds for the Central 
Universities of China (Grant Nos. 2019CDQYWL029 and 2018CDGFCL0002), the Foundation for Innovative Research Groups of the National Natural Science Foundation of China (Grant No. 51421001), and the "111" project (B16007) by the Ministry of Education. The authors would like to thank Shiwei Pan from University of Science and Technology Beijing for help with preparation of traditional cast 7055 alloy.

\section{REFERENCES}

1. J.C. Williams and E.A. Starke: Acta Mater., 2003, vol. 51, pp. 5775-99.

2. M. Dumont, W. Lefebvre, B. Doisneau-Cottignies, and A. Deschamps: Acta Mater., 2005, vol. 53, pp. 2881-92.

3. J. Ren, R.C. Wang, Y. Feng, C.Q. Peng, and Z.Y. Cai: Vacuum, 2019, vol. 161, pp. 434-42.

4. H. She, D. Shu, J. Wang, and B.D. Sun: Mater. Charact., 2016, vol. 113, pp. 189-97.

5. S.D. Liu, C.B. Li, S.Q. Han, Y.L. Deng, and X.M. Zhang: $J$. Alloys Compd., 2015, vol. 625, pp. 34-43.

6. M.M. Sharma, M.F. Amateau, and T.J. Eden: Acta Mater., 2005, vol. 53, pp. 2919-24.

7. J.M. Schreiber, Z.R. Omcikus, T.J. Eden, M.M. Sharma, V. Champagne, and S.N. Patankar: J. Alloys Compd., 2014, vol. 617 , pp. $135-39$.

8. H.C. Yu, M.P. Wang, Y.L. Jia, Z. Xiao, C. Chen, Q. Lei, Z. Li, W. Chen, H. Zhang, Y.G. Wang, and C.Y. Cai: J. Alloys Compd., 2014, vol. 601, pp. 120-25.

9. B. Liu, Q. Lei, L.Q. Xie, M.P. Wang, and Z. Li: Mater. Des., 2016, vol. 96, pp. 217-23.

10. X.D. Wang, Q.L. Pan, L.L. Liu, S.W. Xiong, W.Y. Wang, J.P. Lai, Y.W. Sun, and Z.Q. Huang: Mater. Charact., 2018, vol. 144 , pp. 131-40.
11. Y.G. Yang, Y.T. Zhao, X.Z. Kai, Z. Zhang, H. Zhang, R. Tao, G. Chen, H.S. Yin, and M. Wang: Mater. Res. Express., 2018, vol. 5, pp. 1-21.

12. Y. Liu, D.M. Jiang, W.L. Xie, J. Hu, and B.R. Ma: Mater. Charact., 2014, vol. 93, pp. 173-83.

13. P.F. Jia, Y.H. Cao, Y.D. Geng, L.Z. He, N. Xiao, and J.Z. Cui: Mater. Sci. Eng. A, 2014, vol. 612, pp. 335-42.

14. Z.Y. Guo, G. Zhao, and X.-G. Chen: Mater. Charact., 2015, vol. 102 , pp. $122-30$.

15. K.E. Knipling, D.C. Dunand, and D.N. Seidman: Metall. Mater. Trans. A., 2007, vol. 38A, pp. 2552-63.

16. M.S. Vladivoj Ocenasek: Mater. Charact., 2001, vol. 47, pp. $157-62$.

17. Z.-H. Jia, J.-P. Couzinie, N. Cherdoudi, I. Guillot, L. Arnberg, P. Asholt, S. Brusethaug, B. Barlas, and D. Massinon: Trans. Nonferr. Met. Soc. China., 2012, vol. 22, pp. 1860-65.

18. D. Tsivoulas and J.D. Robson: Acta Mater., 2015, vol. 93, pp. 73-86.

19. J.D. Robson and P.B. Prangnell: Acta Mater., 2001, vol. 49, pp. 599-613.

20. J.D. Robson: Mater. Sci. Eng. A, 2002, vol. 338, pp. 219-29.

21. F.J. Humphreys: Acta Metall., 1977, vol. 25, pp. 1323-44.

22. F.J. Humphreys and M. Hatherly: Recrystallization and Related Annealing Phenomena, 2nd ed., Elsevier Science Publishers, New York, 2004, pp. 285-318.

23. W.T. Huo, J.T. Shi, L.G. Hou, and J.S. Zhang: J. Mater. Process. Technol., 2017, vol. 239, pp. 303-14.

24. Q.H. Zang, H.S. Yu, Y.S. Lee, M.S. Kim, and H.W. Kim: Mater. Charact., 2019, vol. 151, pp. 404-13.

25. C. Schwarze, R. Darvishi Kamachali, and I. Steinbach: Acta Mater., 2016, vol. 106, pp. 59-65.

26. L. Vanherpe, N. Moelans, B. Blanpain, and S. Vandewalle: Comput. Mater. Sci., 2010, vol. 49, pp. 340-50.

27. K. Chang, J. Kwon, and C.K. Rhee: Comput. Mater. Sci., 2018, vol. 142 , pp. $297-302$

28. E. Nes, N. Ryum, and O. Hunderi: Acta Metall., 1985, vol. 33, pp. 11-22.

Publisher's Note Springer Nature remains neutral with regard to jurisdictional claims in published maps and institutional affiliations. 